\title{
Improving Daytime Planetary Boundary Layer Height Determination from CALIOP: Validation Based on Ground-Based Lidar Station
}

\author{
Zhao Liu, ${ }^{1,2}$ Augustin Mortier, ${ }^{3,4}$ Zhengqiang Li, ${ }^{1}$ Weizhen Hou, ${ }^{1}$ Philippe Goloub, ${ }^{3}$ \\ Yang Lv, ${ }^{1,2}$ Xingfeng Chen, ${ }^{1}$ Donghui Li, ${ }^{1}$ Kaitao Li, ${ }^{1}$ and Yisong Xie ${ }^{1}$ \\ ${ }^{1}$ State Environmental Protection Key Laboratory of Satellite Remote Sensing, Institute of Remote Sensing and Digital Earth, \\ Chinese Academy of Sciences, Beijing 100101, China \\ ${ }^{2}$ University of Chinese Academy of Sciences, Beijing 100049, China \\ ${ }^{3}$ Laboratoire d'Optique Atmosphérique, Université Lille 1, 59655 Villeneuve-d'Ascq, France \\ ${ }^{4}$ Norwegian Meteorological Institute (MetNo), 0313 Oslo, Norway \\ Correspondence should be addressed to Zhengqiang Li; lizq@radi.ac.cn
}

Received 16 January 2017; Accepted 13 April 2017; Published 4 June 2017

Academic Editor: Gabriele Curci

Copyright @ 2017 Zhao Liu et al. This is an open access article distributed under the Creative Commons Attribution License, which permits unrestricted use, distribution, and reproduction in any medium, provided the original work is properly cited.

\begin{abstract}
An integrated algorithm by combining the advantages of the wavelet covariance method and the improved maximum variance method was developed to determine the planetary boundary layer height (PBLH) from the Cloud-Aerosol Lidar with Orthogonal Polarization (CALIOP) measurements, and an aerosol fraction threshold was applied to the integrated algorithm considering the applicability of the two methods. We compared the CALIOP retrieval with the measurements of PBLH derived from nine years of ground-based Lidar synchronous observations located in Lille, north of France. The results indicate that a good correlation $(R \geq 0.79)$ exists between the PBLHs derived from CALIOP and ground-based Lidar under clear sky conditions. The mean absolute differences of PBLHs are, respectively, of $206 \mathrm{~m}$ and $106 \mathrm{~m}$ before and after the removal of the aloft aerosol layer. The results under cloudy sky conditions show a lower agreement $(R=0.48)$ in regard of the comparisons performed under clear sky conditions. Besides, the spatial correlation of PBLHs decreases with the increasing spatial distance between CALIOP footprint and Lille observation platform. Based on the above analysis, the PBLHs can be effectively derived by the integrated algorithm under clear sky conditions, while larger mean absolute difference (i.e., $527 \mathrm{~m}$ ) exists under cloudy sky conditions.
\end{abstract}

\section{Introduction}

The planetary boundary layer (PBL) is part of the earth's atmosphere, which is directly influenced by the earth's surface. PBL has an important influence on energy, moisture, momentum, and material exchange between the surface and the atmosphere. Weather and air pollution are related to dynamic variations of PBL processes $[1,2]$, and pollutants are trapped in the PBL and fog also occurs within it [3]. It is important to know the planetary boundary layer height (PBLH) in order to study the weather forecast and air pollution. The PBLH is an important meteorological parameter for us (e.g., the vertical extent of the PBL can be investigated with the retrieval of the PBLH).
Based on the abrupt change in multiple meteorological parameters taking place at the top of the PBL, several methods are available to estimate the PBL height. The climatological analysis based on radiosonde observations is a traditional technique for determination of PBL structure [4-7]. Seven different methods were applied to estimate the PBLH based on radiosonde data (e.g., temperature, potential temperature, virtual potential temperature, relative humidity, and specific humidity), and the uncertainties of the PBLH can reach up to several hundred meters due to the parameters error [7]. In addition, remote sounding systems (e.g., Lidar, wind profiler, and Sodar) are another category of active techniques for estimating the PBL heights [8-12]. Lidar is particularly sensitive to the intensity change of Lidar backscatter signals 
(e.g., the PBL contains higher aerosol loading than the overlying troposphere), so it has a larger backscatter in the Lidar signals and seems to be the most appropriate for continuous observations of PBL $[13,14]$. Particularly, the ground-based Lidar can provide continuous observations of PBLH with high vertical and temporal resolution. During the day, due to the heating effects of solar radiation, a sharp gradient of aerosol concentration exists between the mixing layer and upper atmosphere. Thus, the PBLH can be obtained by searching for the local maximum of the vertical gradient of the backscattered signals [15]. On the basis of this principle, there are several main methods for detection of PBLH, such as gradient method, standard variance method, iterative curvefitting method, and wavelet covariance method [16-20]. In addition, some new algorithms were also proposed for detecting the layer boundary from Lidar signal. The linear segmentation and nonlinear segmentation algorithms were proposed to determine the aerosol boundary with high precision [21, 22].

Many researchers have studied the differences of different inversion methods on determination of PBLH, and the integrated method has been applied to the estimates of PBLH based on observations by ground-based Lidar. Lammert and Bösenberg [23] compared the differences of the convective boundary layer (CBL) height between the maximum variance method and gradient method; this showed that the combination of these two methods provides effective estimates of boundary layer height at least under convective conditions. Sawyer and Li [18] estimated PBLHs by combining the wavelet covariance and iterative curve-fitting method. According to the comparison results of PBLHs derived from observations by ground-based Lidar and radiosonde, the regression $R^{2}$ values are above 0.5 both in cloudy cases and in cloud-free cases.

With the development of active remote sensing technique, the space-borne Lidar can provide global observations of aerosol vertical distributions, which makes it possible to estimate the PBLH from space-based Lidar. The CloudAerosol Lidar and Infrared Pathfinder Satellite Observation (CALIPSO) is a joint NASA-CNES satellite launched in 2006; the Cloud-Aerosol Lidar with Orthogonal Polarization (CALIOP) aboard the CALIPSO provides observations of aerosol and cloud from space. Due to the constraints of the power and integration time of space-borne Lidar, CALIOP has a low signal-to-noise ratio. This makes the conventional methods (e.g., gradient method) more difficult to apply to CALIOP data. Indeed, it is more difficult to search for vertical gradients in noisy profiles. This is one of the main reasons why no CALIOP PBLH product is available yet. However, due to the great significance of quantitative detection of global PBLH derived from CALIOP, studies on the determination of PBLH from CALIOP observations have attracted more and more attention.

Jordan et al. [24] used the maximum variance method to estimate the PBL height from CALIPSO observations over the western hemisphere and Africa. The results showed that the PBLHs from Goddard Earth Observing System-Version 5 (GEOS-5) model PBL heights are within 25\% relative error of the PBL heights from CALIPSO estimates. McGrathSpangler and Denning [25] used the same maximum variance method to evaluate summertime PBL depth over North America. In addition, global analysis of the depth of daytime PBL was made from CALIPSO Lidar, and the result indicated that the PBL depths at about half of the airport locations agree with $25 \%$ of the CALIPSO estimates [26]. Zhang et al. [27] obtained the PBLH from CALIOP over China by combining the Haar wavelet and the maximum variance method. A total mean absolute difference of $170 \mathrm{~m}$ has been found for the PBLH retrieved from CALIOP on the one hand and from a ground-based radiosonde on the other hand.

Previous studies have shown that both the maximum variance technique and the wavelet covariance technique have their own advantages [24]. In general, the maximum variance technique is more robust for the clean air and partly cumulus convection case, while the wavelet covariance technique is more effective for a turbid atmosphere with high backscattering in the PBL. Until now, the maximum variance method is the main method for estimating the PBLH from CALIOP observations; little research has focused on the combination of these two methods. In addition, a sharp gradient of backscatter can be found with the increase of altitude starting from the bottom of the aerosol layer in the PBL, which is corresponding to a large variance that might be confused with the large variance identifying the top of the PBL. For that purpose, this work presents a new algorithm, based on the maximum variance technique developed by Jordan et al. [24], with improved preliminary detection of the sharp gradients that are nonrelated to the PBL. The validation of this method relies on comparisons with PBLH derived from nine years of ground-based Lidar synchronous observations located in Lille, north of France.

The rest of this paper is organized as follows. Sections 2 and 3 present the data and the method of estimates and analysis of PBLH, respectively. In Section 4, cases study and validation of PBLH from observations by ground-based Lidar are completed. Section 5 presents the conclusions.

\section{Data}

2.1. CALIOP Dataset. The CALIOP aboard CALIPSO provides the vertical profiles of elastic backscatter from a near nadir-viewing geometry. Due to the initial laser beam diameter and its divergence, the footprint diameter is about $70 \mathrm{~m}$ and can provide the vertical observations of aerosol and cloud at an interval of $333 \mathrm{~m}$ resolution in the direction along the CALIOP track [28] during both day and night phases of the orbit. CALIPSO belongs to the afternoon (A-train) constellation of satellites with a $705 \mathrm{~km}$ sun-synchronous orbit. The A-train crosses the equator each afternoon at around 1:30 p.m. local time with a 16-day repeat cycle. CALIOP performs measurements at the two wavelengths of $532 \mathrm{~nm}$ and $1064 \mathrm{~nm}$ with an energy of $110 \mathrm{~mJ}$. The $532 \mathrm{~nm}$ band has two polarized channels, including horizontal and perpendicular directions [29]. Currently, CALIOP provides Level 1B and Level 2 products. Level 1B products contain the total attenuated backscatter at $532 \mathrm{~nm}$ and $1064 \mathrm{~nm}$ and the perpendicular attenuated backscatter at $532 \mathrm{~nm}$. Level 2 products contain the cloud and 
aerosol layers information, cloud and aerosol profiles information, and Vertical Feature Mask (VFM) data. The VFM contains the information of classification of cloud and aerosol and their subtypes.

In this paper, two types of data were chosen for the retrieval of PBL heights: (1) total attenuated backscatter at $532 \mathrm{~nm}$ from Level $1 \mathrm{~B}$ data, which has a horizontal resolution of $333 \mathrm{~m}$ and a vertical resolution of $30 \mathrm{~m}$ from $-0.5 \mathrm{~km}$ to $8.2 \mathrm{~km}$, and (2) Level 2 Vertical Feature Mask (VFM) that contains the information of classification of cloud and aerosol and their subtypes. In this work, we used the CALIOP data ranging from 2007 to 2015. In order to avoid the influence of the residual layer during nighttime and due to the great significance of daytime boundary layer detection, all of the PBLH results in this study were estimated from daytime observations.

2.2. Ground-Based Lidar Dataset. Because the space-borne Lidar provides the observations of aerosol from space by means of laser footprint, thus it has a limited spatial coverage on the earth's surface. Therefore, it is a little difficult to validate the space-borne Lidar measurements from the spatial and temporal (especially spatial) synchronous observations by ground-based Lidar. The data used in this study is acquired by the ground-based Lidar in a site in Lille, north of France. This ground-based Lidar belongs to the Laboratoire d'Optique Atmospherique (LOA). Figure 1 shows an example of the position relation between the CALIOP footprints and Lidar site $\left(50.6^{\circ} \mathrm{N}, 3.1^{\circ} \mathrm{E}\right)$. The average distance between CALIOP footprints and Lille Lidar site is around $15 \mathrm{~km}$. The proximity of CALIOP footprint from the ground-based station makes of Lille a location of particular interest for comparison exercises. Indeed, in most of the similar studies, this distance ranges between 30 and $50 \mathrm{~km}$ (e.g., [27]). The Lidar at Lille site is a monoaxial Cimel Micropulsed Lidar (CAML CE370) that provides attenuated backscatter profiles at $532 \mathrm{~nm}$ up to a height of $30 \mathrm{~km}$. The profiles are available with a time resolution of $1 \mathrm{~s}$ and a vertical resolution of $15 \mathrm{~m}$. The Lidar was set up in 2007 and has been running continuously since then. The use of the 2007-2015 dataset allows maximizing the number of comparisons with CALIOP. The estimation method of PBLH was described in Section 3.2.

2.3. Sun Photometer Dataset. In addition to the Lidar dataset, the Sun Photometer measurements performed with the CE318 Cimel Sun Photometer on Lille observation platform were used for analyzing the atmosphere and aerosol. This instrument was integrated into the Aerosol Robotic Network (AERONET) and maintained by Lille University. The standard CE-318 Cimel Sun Photometer consists of bands with center wavelengths of $340,380,440,500,675,870,936,1020$, and $1640 \mathrm{~nm}$ [30]. The Aerosol Optical Depth (AOD) and Ångström exponent can be obtained from the ground-based measurements of direct solar irradiance. For consistency purposes with the Lidar wavelength, AOD were interpolated at $532 \mathrm{~nm}$ from 440 and $870 \mathrm{~nm}$ channels.

\section{Methods}

3.1. Determination of PBLH by Space-Borne Lidar. In this study, we developed an integrated algorithm for determining the daytime PBLH from the attenuated backscatter at $532 \mathrm{~nm}$. This method combines the advantages of wavelet covariance transform and the improved maximum variance method. In order to ensure the stability and reliability of the results, some preliminary steps need to be considered. Firstly, due to the large noise present in CALIOP profiles during the daytime, the backscatter profiles need to be averaged horizontally along the track to improve the signal-to-noise ratio [29]. In this paper, the profiles were horizontally averaged over $15 \mathrm{~km}$ and were vertically filtered along the altitude. Secondly, the cloud screening based on VFM was applied to reduce the effect of the clouds. Furthermore, according to the discrimination of aerosol fraction, the optimization scheme was developed to estimate the PBLH by considering the advantages of two methods (see Section 3.1.4).

3.1.1. Wavelet Covariance Transform. As a means of detecting sharp changes in a signal, the wavelet covariance transform $W_{f}(a, b)$ is defined as [31]

$$
h\left(\frac{z-b}{a}\right)= \begin{cases}+1: & b-\frac{a}{2} \leq z \leq b \\ -1: & b \leq z \leq b+\frac{a}{2} \\ 0: & \text { elsewhere }\end{cases}
$$

where $z$ is the altitude, $h$ is the Haar wavelet function, $a$ is the spatial extent of wavelet function (also known as the dilation of the wavelet function), and $b$ is the location at which the Haar function is centered (also known as the translation of the wavelet function). If we introduce into the backscatter profile $S(z)$, the convolution of Haar function $h$ with $S(z)$ is given by the following equation:

$$
W_{f}(a, b)=\frac{1}{a} \int_{z_{b}}^{z_{t}} S(z) \cdot h\left(\frac{z-b}{a}\right) d z,
$$

where $z_{b}$ and $z_{t}$ are the lower and upper limits of the profile, respectively.

Because a strong negative gradient of backscatter is presented between the PBL and the free troposphere, the top of the PBL can be identified by searching for the local maximum in $W_{f}(a, b)$. Davis et al. [14] showed that, for simple cases, the PBL depth can be easily identified by the maximum of $W_{f}(a, b)$. The choice of $a$ does not seem to be crucial, but it becomes important under less ideal conditions. Figure 2 shows an example of the wavelet covariance transform using multiple dilations for CALIOP data. Figure 2(c) shows the comparison of top heights of PBL at the points of nearest spatial and temporal coincidence between CALIOP footprints and Lille Lidar site. The PBLH values are relative to surface height, and the difference of PBLH derived from CALIOP and CE370 is $74 \mathrm{~m}$. In practice, the result bias of PBLH estimated by the wavelet covariance transform method can be decreased by selecting multiple wavelet scales. After a large number of 


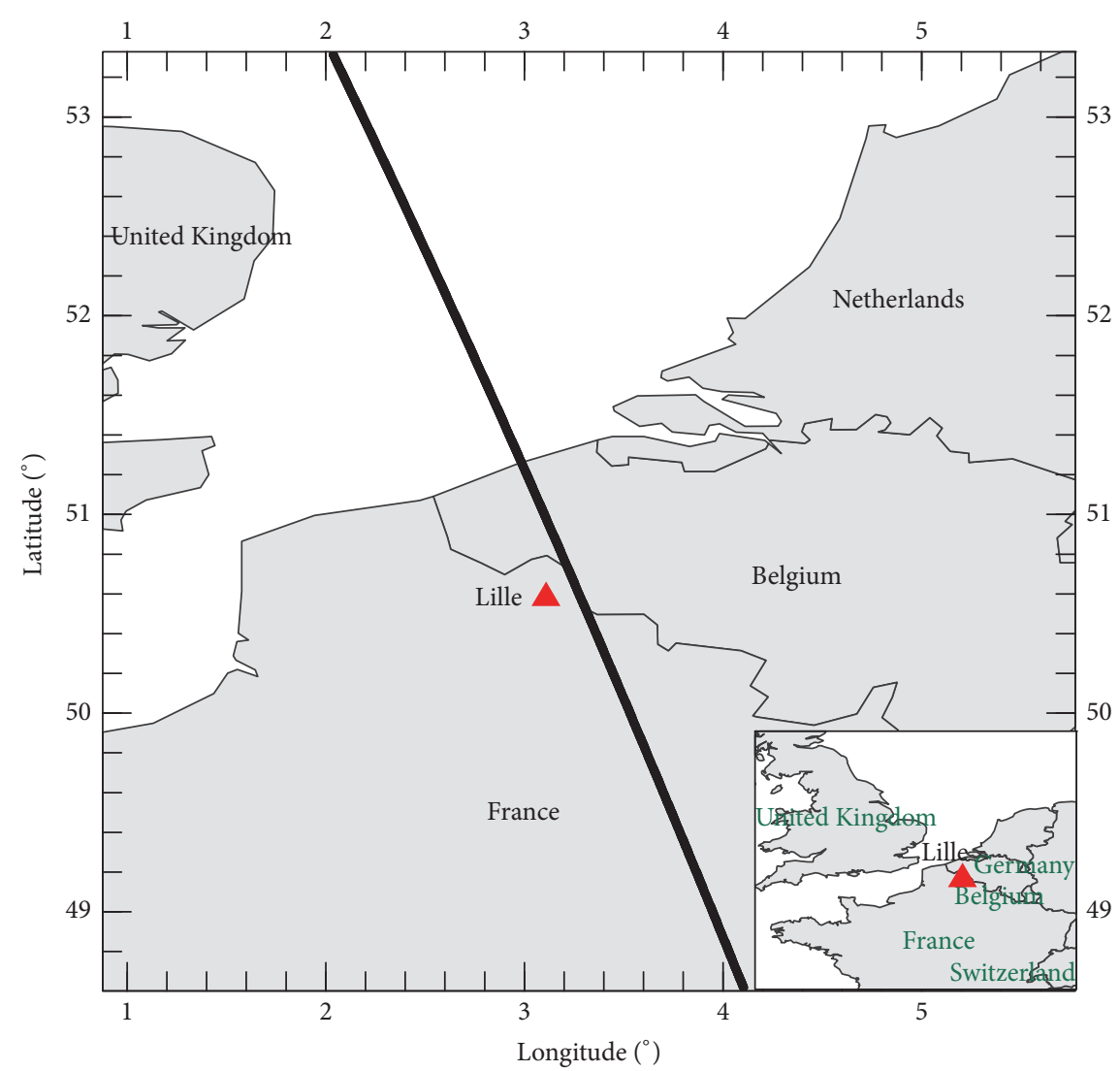

FIGURE 1: Location of the Lille Lidar site; the black solid lines signify the footprints of CALIPSO orbit. The closest distance between CALIOP footprints and the Lille Lidar site is $14.94 \mathrm{~km}$, which was acquired at 12:50 UTC (daytime), February 27, 2008.

experiments, six wavelet scale factors of 450-600 m (15-20 bins) were selected and the mean profile of wavelet covariance coefficients was applied to estimate the PBLH.

Based on the principle mentioned above, a detection method was adopted to estimate the PBLH. Firstly, we searched for the local maximum in the vertical wavelet covariance coefficient starting from the surface. Secondly, we chose all local maxima of the wavelet covariance coefficients that correspond to a maximum in the attenuated backscatter at $532 \mathrm{~nm}$ itself in the meantime. Finally, the occurrence of a maximum in the local maxima of the wavelet covariance coefficients chosen by the above step was identified as the PBL height.

3.1.2. Improved Maximum Variance Method. The maximum variance method was based on the work of Melfi et al. [13]. Due to the sharp decrease in the vertical profile of backscattered signals between PBL top and free troposphere above, there is a local maximum in the vertical gradient of backscattered signals. Jordan et al. [24] estimated the top of the PBL by searching for a local maximum in the vertical standard deviation starting from the surface combined with a maximum in the magnitude of the backscatter.

Due to the sharp gradient caused by the sharp increase in backscatter signal mentioned in Section 1, an improved maximum variance method was developed based on the technique by Jordan et al. [24], and we added a condition to remove this false sharp gradient, which was given by the following equation:

$$
\begin{aligned}
& \beta^{\prime}(i)>\beta^{\prime}(i+1), \\
& \beta^{\prime}(i)>\beta^{\prime}(i+2),
\end{aligned}
$$

where $\beta^{\prime}$ is the total attenuated backscatter at $532 \mathrm{~nm}$ and $i$ is the position of the backscatter signal in vertical profiles of backscatter, which is corresponding to the currently local maximum of standard deviation that needed to be judged. The value of $i$ increases with the increase of altitude, and $i+1$ and $i+2$ are the positions of the bin corresponding to the backscatter signal.

Figures 3(a) and 3(b) show the vertical profiles of total attenuated backscatter at $532 \mathrm{~nm}$ acquired, respectively, from CALIOP and CE370 on Lille site at 12:51 UTC (13:51 local time) on December 31, 2015. The nearest distance between CALIOP footprints and CE370 Lidar site is, for this day, $8.7 \mathrm{~km}$. Figure $3(\mathrm{a})$ shows the PBLH results derived by the maximum variance method developed by Jordan et al. and the improved maximum variance method. The derived PBL top heights are $0.67 \mathrm{~km}$ and $0.94 \mathrm{~km}$ above sea level, respectively. Correspondingly, the derived PBLHs are $0.64 \mathrm{~km}$ and $0.91 \mathrm{~km}$ above surface height, respectively, with a difference of $0.27 \mathrm{~km}$. 


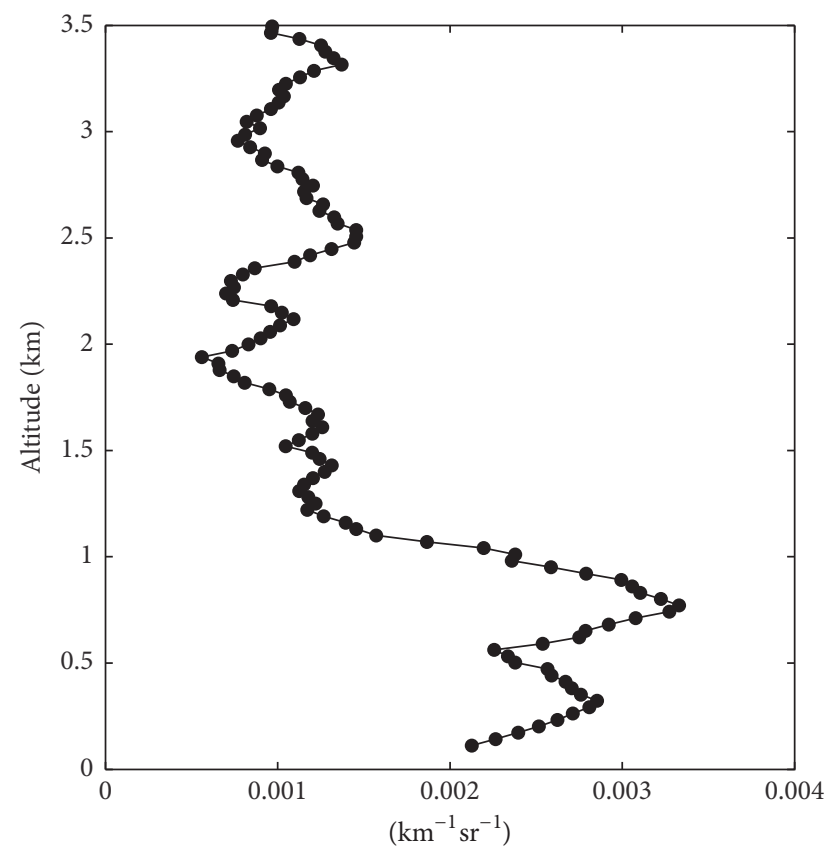

- Backscatter

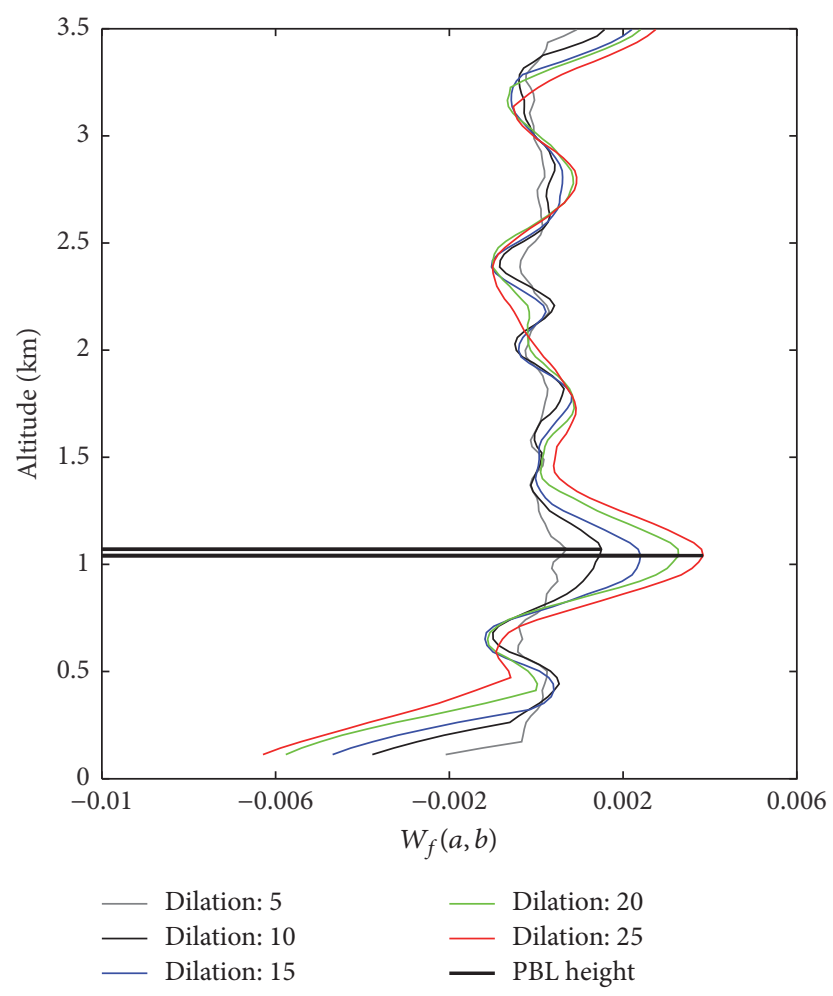

(b)

(a)

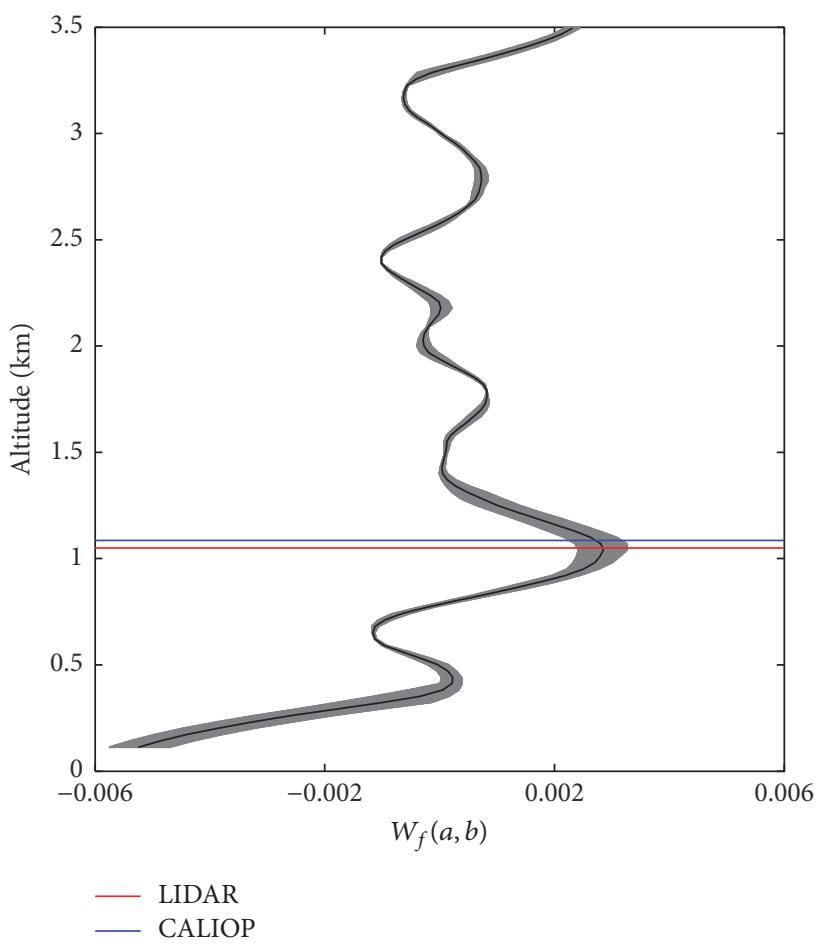

(c)

FIgURE 2: Example of the wavelet covariance transform. The CALIOP profile was acquired at 12:51 UTC (daytime) on September 4, 2013. (a) The total attenuated backscatter at $532 \mathrm{~nm}$ acquired by CALIOP, (b) result of the covariance transform for different wavelet dilations applied to the profile in (a), and (c) result of top heights of PBL derived from CALIOP and ground-based Lidar, respectively. 


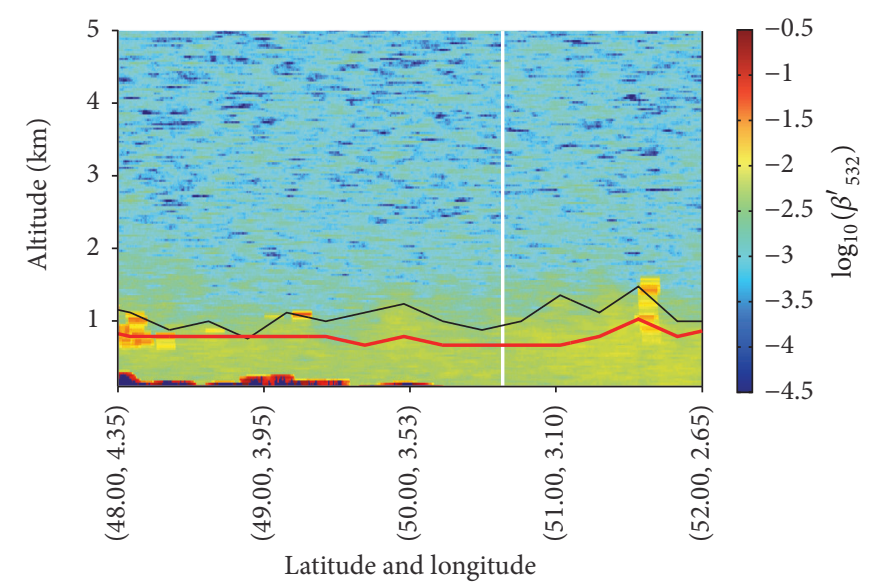

(a) CALIPSO

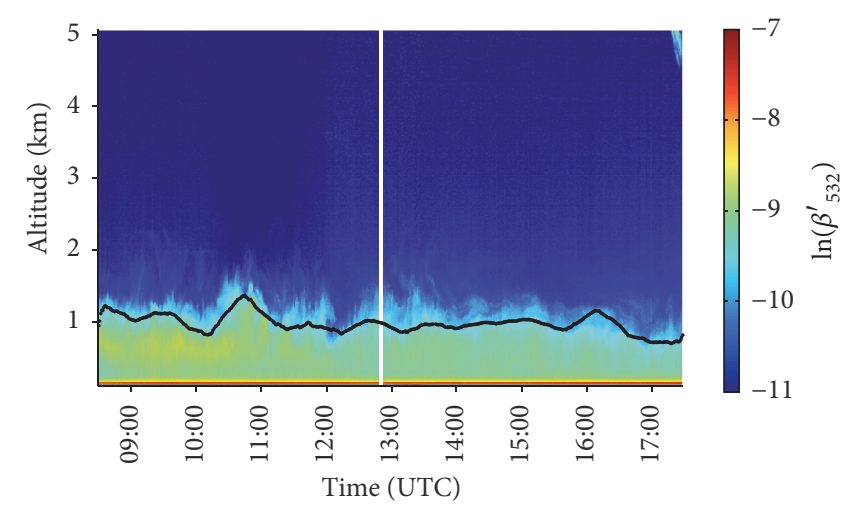

(b) CE370

FIGURE 3: Vertical profiles of total attenuated backscatter at $532 \mathrm{~nm}$; (a) was acquired from CALIOP, while (b) was acquired from groundbased Lidar (CE370), which were all measured on December 31, 2015. The PBLH results derived by the maximum variance method developed by Jordan et al. (red bold line) and the improved maximum variance method (black line) are, respectively, shown in (a) along with latitude and longitude, while in (b), the PBLH results (black points) were derived by wavelet method from CE370 observations during daytime, which are relative to sea level. The vertical white solid lines in (a) and (b) indicate the points of the nearest spatial and temporal coincidence between the CE370 Lidar site and the CALIOP footprint.

In Figure 3(b), the PBLH derived by CE370 is $0.935 \mathrm{~km}$ above ground surface, with a difference of only $25 \mathrm{~m}$ compared to the PBLH estimated by improved maximum variance method.

3.1.3. Cloud Masking. Because CALIOP observes the atmosphere by looking downward from space, the clouds (especially the thick clouds) involve significant attenuation of the backscatter signal in underlying layers. This makes the detection of the PBL height difficult in cloudy sky conditions. For this purpose, Level 2 VFM product was applied to eliminate the profiles that contain clouds. Correspondingly, two steps were followed for cloud elimination. Firstly, we calculated the cloud fraction for every vertical profile of backscatter by L2 VFM product. The cloud fraction is defined as the ratio of the number of clouds identified by VFM product to the total number of bins in a backscatter profile. Then, we selected $5 \%$ as the threshold value of cloud fraction for removing the backscatter profiles associated with a higher fraction [32].

3.1.4. Integrated Algorithm. Wavelet covariance transform and maximum variance method have their own limitations for the determination of PBLH. Jordan et al. [24] have shown that if a PBL structure with high backscattering in the PBL exists, the wavelet covariance transform can identify the PBLH very well. On the contrary, in the case of clear atmosphere and partial cumulus convection, it is more robust to use the maximum variance method to identify PBLH. Both of the methods have their own error on the determination of PBLH. Until now, there are few studies focusing on combining the advantages of these two methods, aiming at determining the PBLH from CALIOP observations. In this paper, the wavelet covariance transform and the improved maximum variance

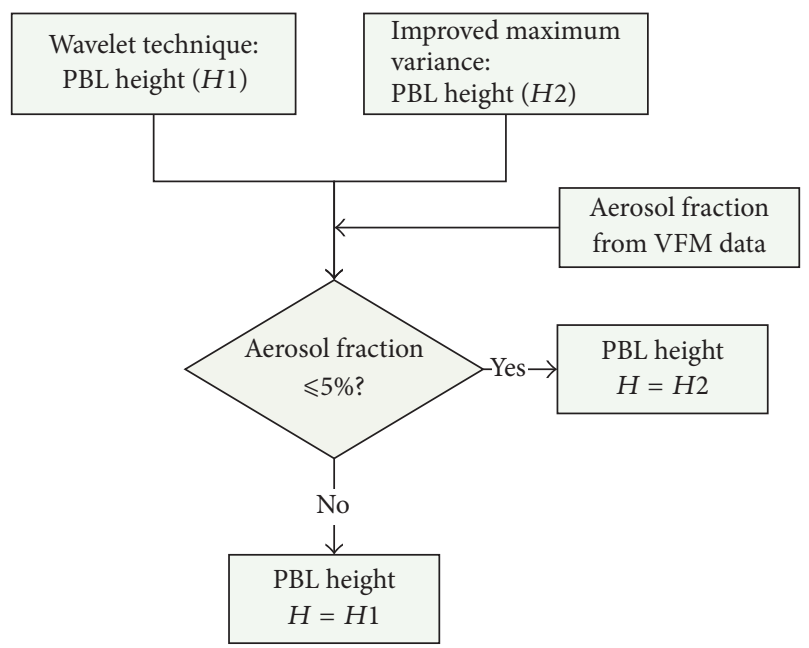

FIGURE 4: The flowchart of the integrated algorithm.

method were combined to estimate the PBLH. The flowchart of the integrated PBLH detection algorithm is shown in Figure 4. Consequently, the PBLH results noted as $H 1$ and $H 2$ were obtained from two methods, respectively.

Considering the applicability of the wavelet covariance transform and improved maximum variance method, the difference between these two methods is mainly on the content of aerosol for a single backscattering profile. In order to process the data and combine the advantages of these two methods, the aerosol fraction was introduced to the integrated algorithm; it is defined as the ratio of the number of aerosol bins identified by VFM product to the total number of bins in a backscatter profile. In order to distinguish different aerosol conditions, a threshold of aerosol fraction should be 


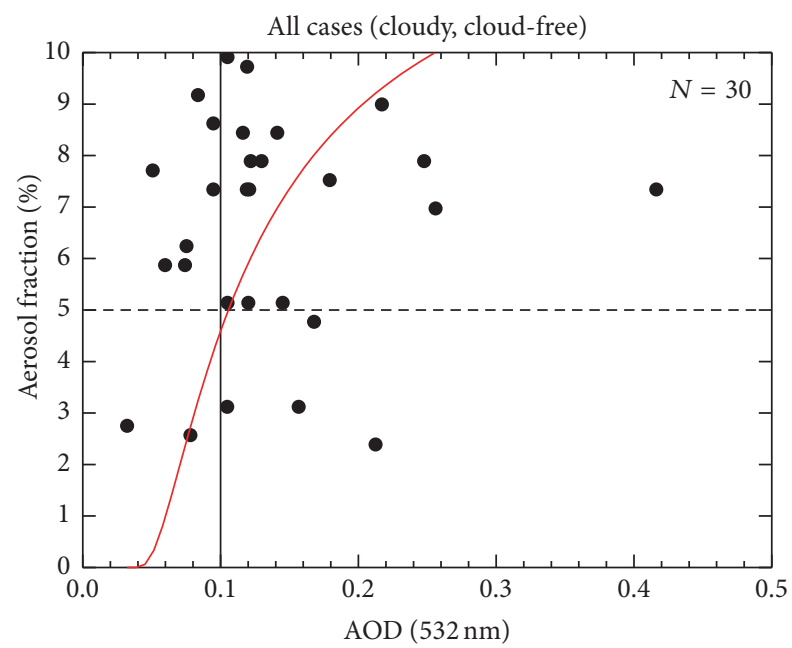

FIGURE 5: The relationship of AOD at $532 \mathrm{~nm}$ and aerosol fraction during CALIOP overpass. The fitting result of the data points (red solid line).

confirmed first. Figure 5 shows the relationship of aerosol fraction and AOD at $532 \mathrm{~nm}$ for all cases (cloudy, cloudfree) during CALIOP overpass. The fitting result of the data points shows that aerosol fraction increases with the increase of AOD. As we know, AOD has a positive correlation with the content of aerosol. Groß et al. [33] pointed out that an AOD of less than 0.1 at $532 \mathrm{~nm}$ over Europe indicates clear sky conditions. Wang et al. [34] chose an AOD equal to 0.12 at $550 \mathrm{~nm}$ over Beijing, China, as the aerosol properties under clear weather conditions. As the red line shows in Figure 5, the aerosol fraction is close to $5 \%$ when the AOD is equal to 0.1 . Thus, the value of $5 \%$ was selected as a suitable threshold of aerosol fraction to distinguish the relatively weak aerosol condition from different aerosol conditions. Then, the PBLH from the corresponding detection method was selected as the appropriate PBLH (e.g., selection of the improved maximum variance method for weak aerosol layer and selection of the wavelet covariance transform method for other aerosol conditions).

In addition, the PBLH was limited to $0.25-5.0 \mathrm{~km}$ above the ground surface [25]. Finally, in order to reduce the abnormal value and improve spatial continuity, the PBLH results should be horizontally averaged over a spatial extent. Winker et al. [29] showed that the estimated detection sensitivity of the CALIOP $532 \mathrm{~nm}$ channel improved with the increase of the window size of horizontal averaging, for example, $1 \mathrm{~km}$, $5 \mathrm{~km}$, and $80 \mathrm{~km}$; these window sizes of horizontal averaging were already specified in L2 VFM product. McGrathSpangler and Denning [25, 26] chose $20 \mathrm{~km}$ and $60 \mathrm{~km}$, respectively. After overall considerations about the quality control and loss of horizontal resolution, the individual PBLH results were horizontally averaged over $30 \mathrm{~km}$ by a running mean. In addition, if the aerosol loading in a backscattering profile is very low (i.e., aerosol fraction $=0 \%$ ), none of the methods will be available to estimate the PBLH in this case. In order to improve the reliability of the PBLH results, the profiles which have an aerosol fraction of 0 were removed.
3.2. Determination of PBLH by Ground-Based Lidar. In order to validate the PBLH results derived from space-based Lidar, the PBLH results obtained from ground-based Lille Lidar station were used. Although the detection techniques for determining the PBLH by ground-based Lidar are already mature, several important instrumental aspects, such as nonlinearity of the detectors and the overlap function, still need to be considered. Besides, the attenuated backscattered signals were averaged over a time period of 20 minutes and were normalized for data preprocessing. In addition, spectral filtering which allows reducing the noise associated with high frequencies vertical variation was applied to the measurements. Clouds conditions were also removed to the PBLH retrieval thanks to filtering based on the vertical variability of the backscatter profiles. The required thresholds are determined from climatologic values, the whole Lille database covering more than 10 years of continuous measurements. The description of the cloud detection method applied on the profiles of backscatter was based on the work of Mortier et al. [35].

Consequently, two different layer heights (i.e., the PBL height and top layer (TL) height) were detected for each profile. The TL refers to the top of the highest aerosol layer if the related vertical gradient is significant enough. This latter retrieval is of particular interest when aerosol layers are transported above the PBL. The principle of the detection method is available in Section 3.1.1, and more details can be found in the work of Mortier [36]. Besides, the detection of TL height was based on Léon et al. [37]. Finally, both PBL and TL heights were averaged over 30 minutes in order to ensure a temporal stability.

\section{Results}

4.1. PBL under Clear Sky Condition. Figures 6(a) and 6(b) show the color images of the daytime total attenuated backscatters at $532 \mathrm{~nm}$ acquired by CALIOP and CE370 on Lille site, as well as the PBLH results for March 7, 2011. According to the estimates of AOD at $532 \mathrm{~nm}$ on Lille site, the nine-year averaged AOD during CALIOP overpass is 0.13 . The average AOD within half an hour during CALIOP overpass is 0.10 on March 7, 2011. The vertical white solid lines in these two figures show the points of the nearest spatial and temporal coincidence between CALIOP footprints and CE370 Lidar site, which were acquired at 12:51 UTC (13:51 local time); the distance between CALIOP footprint and CE370 Lidar site is $12.27 \mathrm{~km}$. In this case, no cloud was detected around the area.

Figure 6(a) indicates the differences of PBLHs retrieved with the three different detection methods detailed in Section 3.1. For cases where aerosol fraction was more than $5 \%$, the PBLHs can be determined effectively by the wavelet method. On the contrary, when the value of aerosol fraction was less than 5\%, the PBLHs can be determined effectively by the improved maximum variance method. Figure 6(b) shows the daily variation of PBL. During daytime, the solar radiation heats up the surface leading to an increasing PBL which reaches a stable state at around 12:30 UTC (13:30 local time). 


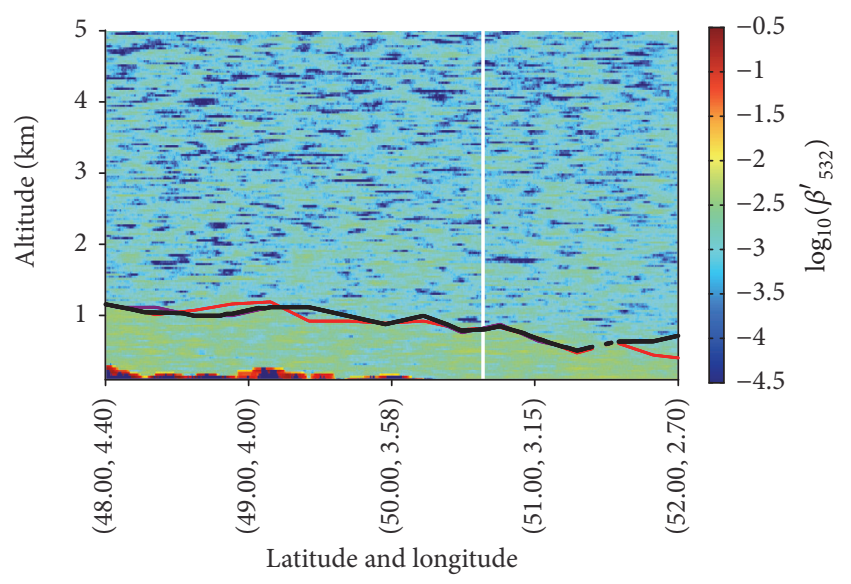

(a) CALIOP

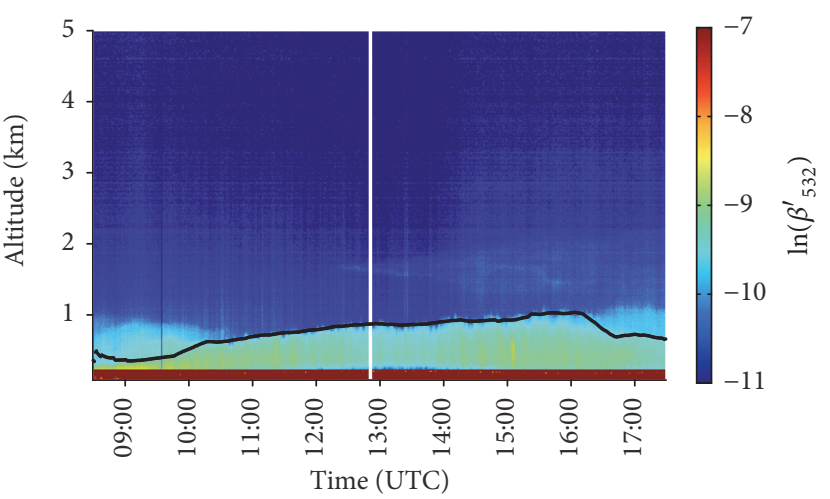

(b) CE370

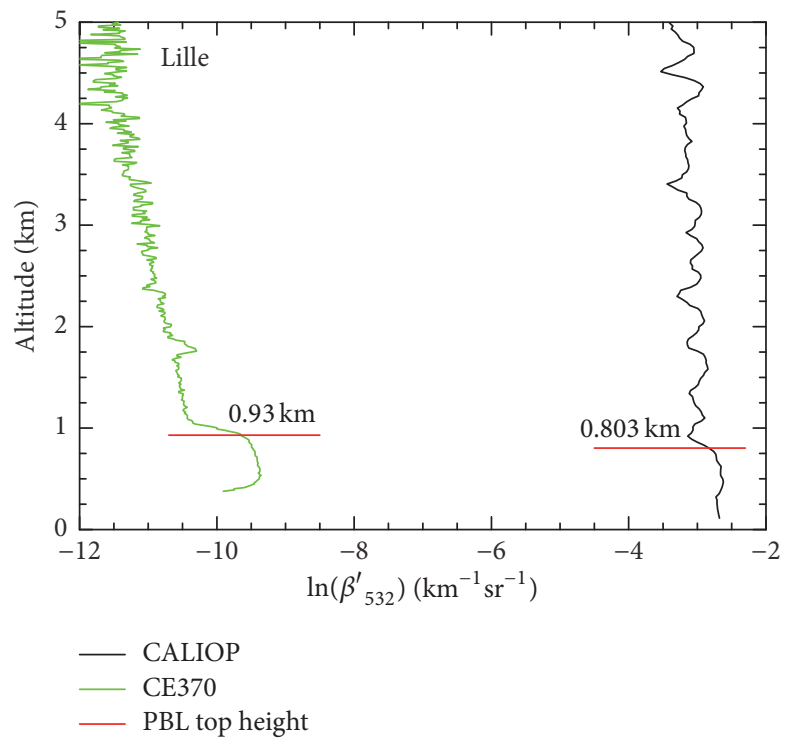

(c)

FIGURE 6: Vertical profiles of total attenuated backscatter at $532 \mathrm{~nm}$ under clear sky conditions, in which (a) is for CALIOP and (b) is for CE370. In (a), the PBLH results derived by wavelet method (red line), improved maximum variance method (purple line), and integrated algorithm (black bold line) are, respectively, shown in the same figure along with latitude and longitude; (b) is similar to Figure 3(b), but for another day. The PBLH results (black points) were derived from CE370 during daytime. The vertical white solid lines in (a) and (b) indicate the points of the nearest spatial and temporal coincidence between CALIOP footprints and CE370 Lidar site, and (c) shows the comparison of vertical profiles of backscatter signals and PBL top height results between CALIOP and ground-based Lidar. The vertical profiles are corresponding to the vertical white solid lines in (a) and (b).

Afterwards, the PBL decreases with the decreasing solar radiation. Figure 6(c) shows the comparison of the vertical profiles of backscatter at $532 \mathrm{~nm}$ between CALIOP and CE370, as well as the PBL height estimated at the coincident point.

The comparison results indicate that the PBLH derived from CALIOP is in good agreement with the one derived from CE370 observations. The PBL top heights are $0.80 \mathrm{~km}$ and $0.93 \mathrm{~km}$ above sea level, respectively. Correspondingly, the PBLHs derived by CALIOP and CE370 are $0.77 \mathrm{~km}$ and $0.87 \mathrm{~km}$ above surface height, respectively. Consequently, it has a difference of $100 \mathrm{~m}$ in this case.
4.2. PBL under Polluted Condition. Similarly, as in Figure 6, Figures 7(a) and 7(b) show the results of PBLHs under polluted condition for April 16, 2014. On this day, the average AOD within half an hour during CALIOP overpass is 0.25 . The points of the nearest spatial and temporal coincidence between CALIOP footprints and CE370 Lidar site were acquired at 12:51 UTC (14:51 local time), and the distance between them is about $11.67 \mathrm{~km}$.

Figure 7(a) shows the differences of PBLHs among different detection methods; it illustrates that the PBLHs are determined effectively by the wavelet method under polluted 


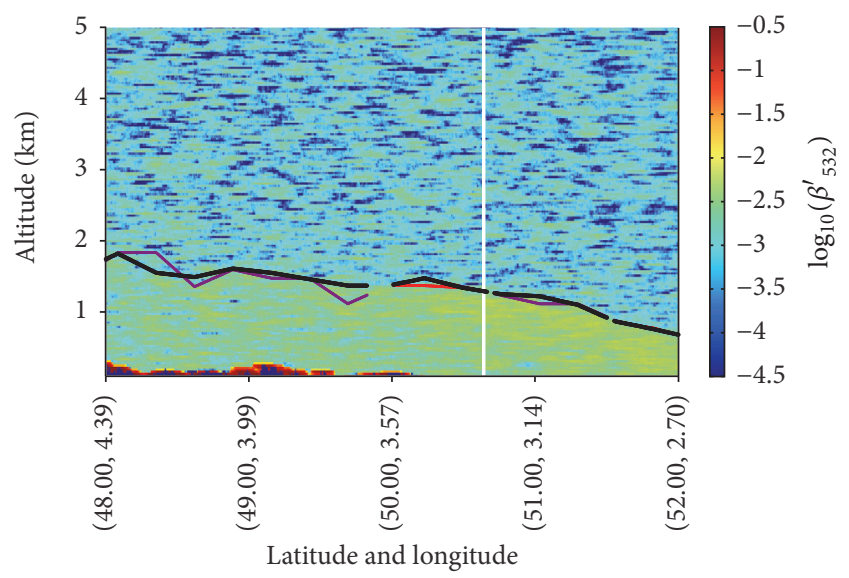

(a) CALIOP

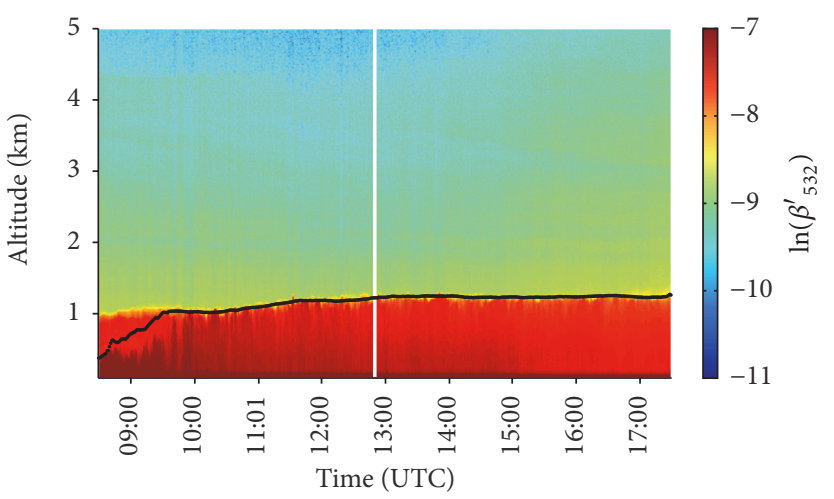

(b) CE370

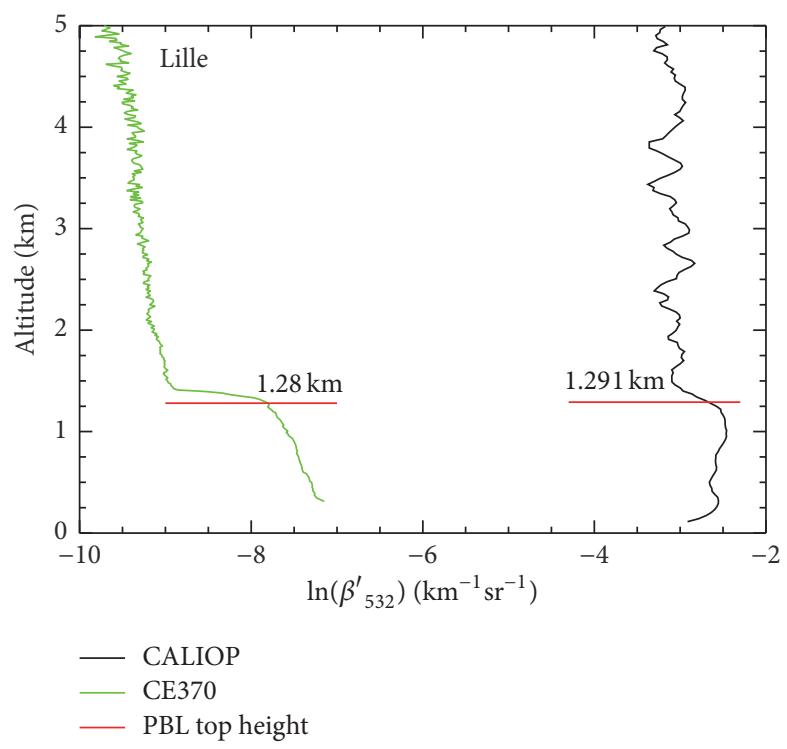

(c)

FIgURE 7: Similar to Figure 6, but for a polluted sky condition.

condition. Figure 7(b) shows that the PBL grows from the morning and reaches a stable state at around 12:00 UTC (14:00 local time). Figure 7(c) is similar to Figure 6(c), but for polluted condition. The result indicates that the PBLHs results derived from CALIOP are in good agreement with CE370. Under polluted condition, the PBL top heights are $1.29 \mathrm{~km}$ and $1.28 \mathrm{~km}$ above sea level, respectively. Correspondingly, the PBLHs results derived by CALIOP and CE370 are $1.26 \mathrm{~km}$ and $1.22 \mathrm{~km}$ above surface height, respectively, which has a difference of $40 \mathrm{~m}$.

4.3. Comparisons of PBL Heights at Different Distance Thresholds. Cloud detection was performed for each profile of backscatter based on the observations by ground-based Lidar. According to the cloud detection method described in Section 3.2, we can determine the presence of clouds in the atmosphere within half an hour during CALIOP overpass. If at least one cloudy backscatter profile is found in all the profiles used in the average of 30 minutes during CALIOP overpass, then the related PBLH is flagged as retrieved in cloudy sky condition. Figure 8 shows the spatial relationship between ground-based Lidar station and CALIOP footprints during CALIOP overpass. Two spatial distances $(20 \mathrm{~km}$ and $50 \mathrm{~km}$ ) were selected to make a comparison of the difference of derived PBLHs. The black circle represents the selected footprint for comparison of the derived PBLHs at different spatial distances.

Figure 9 shows the scatterplot of PBLHs derived from CALIOP versus those results from CE370 for cloud-free cases. The estimates of PBLHs are relative to the surface height. To analyze the effect of distance on the validation accuracy of PBLHs, two representative distances (around $20 \mathrm{~km}$ and $50 \mathrm{~km}$ ) between CALIOP footprints and Lille Lidar site are considered. In Figures 9(a) and 9(b), the high correlation (correlation coefficient $R \geq 0.75$ ) of PBLHs derived from CALIOP and CE370 exists for both distances of $20 \mathrm{~km}$ and $50 \mathrm{~km}$, and the corresponding mean absolute differences are $0.191 \mathrm{~km}$ and $0.210 \mathrm{~km}$, respectively. 


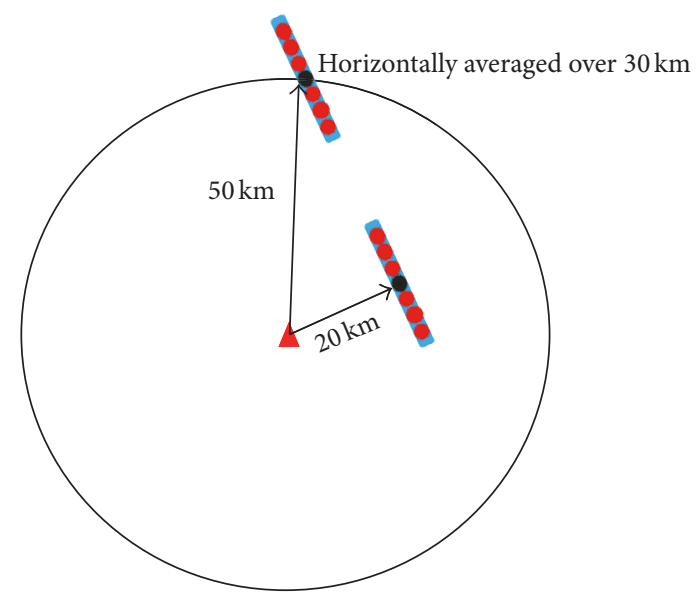

FIGURE 8: Spatial relationship between ground-based Lidar station and CALIOP footprints during CALIOP overpass. The red triangle represents the position of Lille Lidar station, the red circle represents the footprints of CALIOP, the black circle represents the position of CALIOP footprint at the specified spatial distance (e.g., $20 \mathrm{~km}$ and $50 \mathrm{~km}$ ), and the blue rectangle represents $30 \mathrm{~km}$ window size of horizontally running mean for the black circle.

The above analyses imply that the agreement of PBLHs decreases with the increasing spatial distance between CALIOP footprint and Lille Lidar site. There is an actual height difference for the PBL observed at Lille and $50 \mathrm{~km}$ away. Besides, the cloud has a significant impact on the accuracy of PBLHs derived from CALIOP.

4.4. Comparisons of PBL Heights on Time Series. Figure 10(a) shows the comparison of PBLHs derived from CALIOP and CE370 under clear sky conditions on Lille site, and the time period is over nine years from 2007 to 2015. The mean absolute difference of PBLHs derived from CALIOP and CE370 is $0.206 \mathrm{~km}$. Figure 10(b) shows the AOD and Ångström exponent derived from the Sun Photometer within half an hour during CALIOP overpass, and the AOD values are typically around 0.1 in nine years during CALIOP overpass, which implies the clear atmospheric conditions (i.e., low aerosol loading). The Ångström exponent is typically larger than 1, which implies that the small particles are the main particles presented in the atmosphere for Lille site.

Two relatively large absolute differences of PBLHs can be found in Figure 10(a). The absolute difference of PBLH is $0.59 \mathrm{~km}$ on November 23, 2007, and the value of averaged AOD is 0.09 during CALIOP overpass on this day. The corresponding Angström exponent is 0.47 and the aerosol type is urban-industrial. The absolute difference of PBLH is $0.63 \mathrm{~km}$ on March 25, 2012. And the value of averaged AOD is 0.42 during CALIOP overpass on this day.

In addition, we give a threshold value to identify the aloft aerosol layer (e.g., aerosol layer above the PBL). If the difference between the PBL height and TL height for a backscatter profile exceeds this threshold value, the aloft aerosol layer is found. Three threshold values (i.e., $0.5,1.0$, and $1.5 \mathrm{~km}$ ) were used to test the validity of the identification of the aloft aerosol layer. Finally, $0.5 \mathrm{~km}$ was regarded as a suitable threshold to identify the aloft aerosol layer. Based on the judgement mentioned above, we analyzed the difference between PBL height and TL height in the cases where the relatively large absolute differences of PBLH exist. According to the statistical results, all of the differences between PBL height and TL height are larger than $0.5 \mathrm{~km}$. Therefore, the presence of the aloft aerosol layer is the main cause for the large absolute differences of PBLH. The presence of the aloft aerosol layers is also consistent with the corresponding quick look images of the total attenuated backscatters at $532 \mathrm{~nm}$ displayed on the website of LOA.

Because of the aloft aerosol layer overlying the PBL, the significant attenuation in the downward backscatter signals acquired from CALIOP can be found. In addition, the top of the aloft aerosol layer also has a sharp decrease in backscattered signals. As a result, the top height of the aloft aerosol layer is usually falsely identified as the PBL height. Therefore, the aloft aerosol layer has a certain impact on the estimation of PBL height.

4.5. Comparisons of PBL Heights under Different Cloud Conditions. Figure 11 shows the comparisons of PBLHs derived from CE370 and CALIOP at the points of the nearest spatial and temporal coincidence between CALIOP footprints and CE370 Lidar site. All of the nearest spatial distances are within $20 \mathrm{~km}$. The estimates of PBLHs are relative to the surface height. Figures 11(a) and 11(b) are for the cloud-free cases, while Figure 11(c) is for cloudy cases. In Figure 11(a), a high correlation $(R=0.79)$ of PBLHs exists between the scatterplots of PBLHs derived from CALIOP and ground-based Lidar, and the mean absolute difference and the RMSE are $0.206 \mathrm{~km}$ and $0.222 \mathrm{~km}$, respectively. Figure $11(\mathrm{~b})$ shows a higher correlation $(R=0.94)$ after the removal of the effect of the aloft aerosol layer in Figure 11(a). In Figure 11(c), a low correlation $(R=0.48)$ of PBLHs exists between the PBLHs derived from CALIOP and ground-based Lidar under the cloudy cases, and the corresponding mean absolute difference and the RMSE are also large.

The above analysis shows that the PBLHs can be obtained effectively by CALIOP in cloud-free cases; however, the large absolute difference exists in cloudy cases, the value of which is $0.527 \mathrm{~km}$.

Figure 12 presents the comparison results of PBLH derived from CALIOP and CE370. Figures 12(a) and 12(b) quantitatively present the results of comparing the maximum variance method developed by Jordan et al. [24] with the integrated PBLH detection algorithm. The mean absolute differences are $0.571 \mathrm{~km}$ and $0.206 \mathrm{~km}$ in Figures $12(\mathrm{a})$ and 12(b), respectively, which indicates that the accuracy of the PBLH derived by the integrated algorithm is better than that of the maximum variance method.

\section{Conclusions}

In this paper, an improved maximum variance method was developed, and an integrated algorithm by considering both advantages of the wavelet covariance transform and the improved maximum variance method was developed, which 


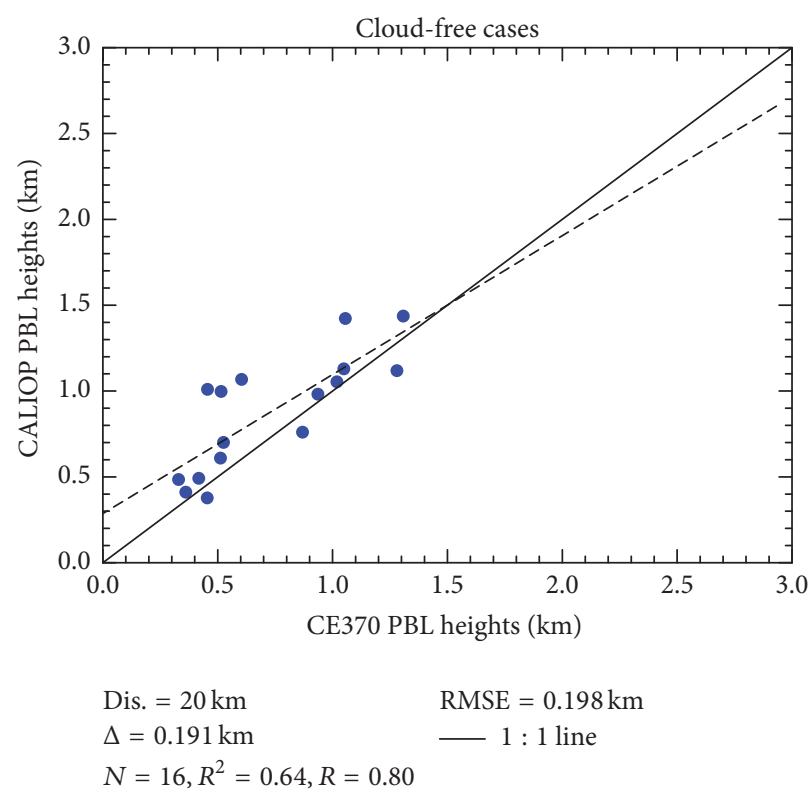

(a)

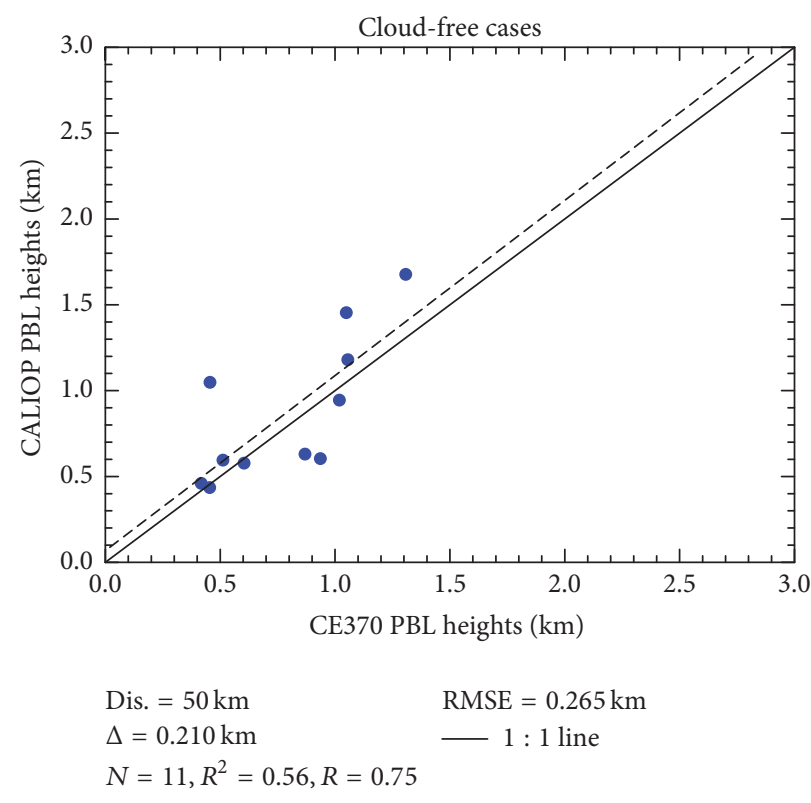

(b)

FIgURE 9: The comparison results of PBLH derived from CALIOP and CE370 in cloud-free cases. (a) For the threshold value of $20 \mathrm{~km}$, (b) for the threshold value of $50 \mathrm{~km}$.

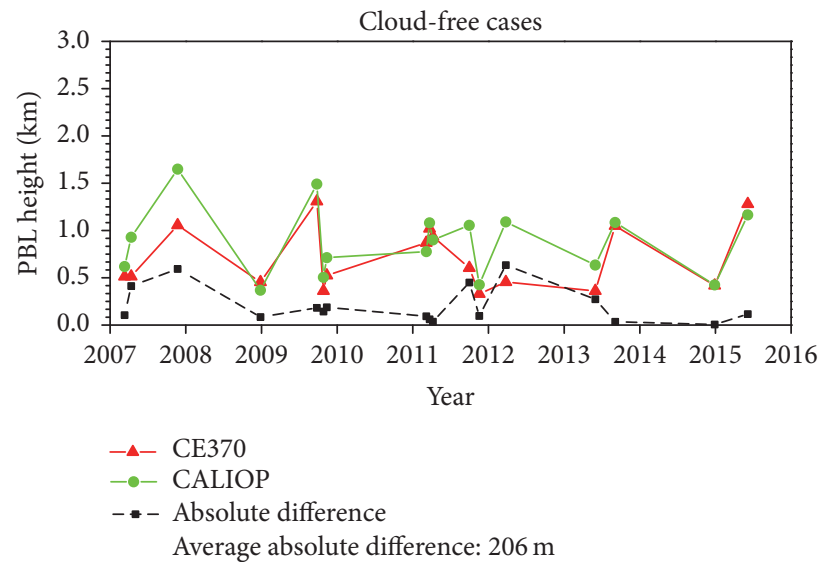

(a)

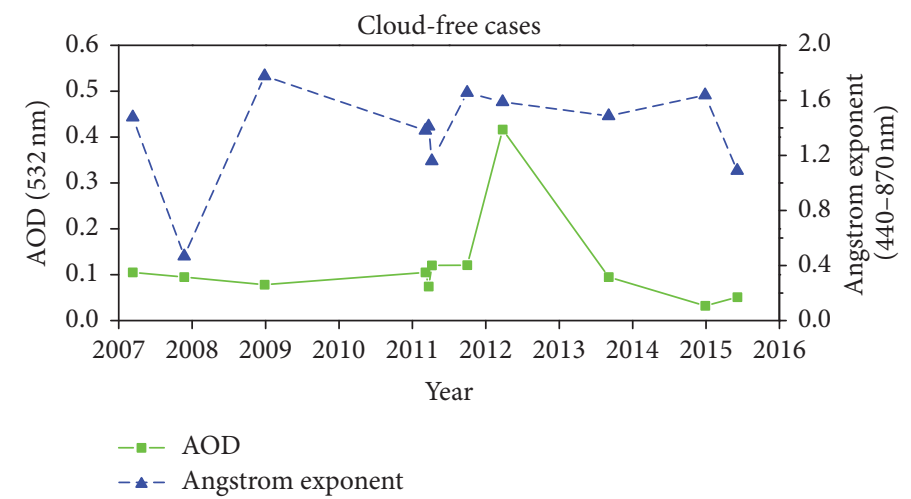

(b)

FIGURE 10: Under clear sky conditions, (a) illustrates the comparison of PBLH at the points of the nearest spatial and temporal coincidence between CALIOP footprints and CE370 Lidar site. (b) demonstrates the averaged AOD and Ångström exponent derived from the Sun Photometer within half an hour during CALIOP overpass.

aims to obtain the reliable PBLHs from the CALIOP observations. Besides, an aerosol fraction threshold was applied to the integrated algorithm considering the applicability of these two methods, in order to solve the problem of determining PBLH under different aerosol conditions (e.g., weak aerosol layer or another aerosol layer exists). Due to the effects of clouds (especially the thick clouds) on the backscattered signals acquired from space-borne CALIOP, the cloud elimination based on VFM data was adopted. In addition, a height threshold was given to identify the aloft aerosol layer. The validation of PBLH estimated by CALIOP has been performed using nine years of synchronous observations based on the data from Lille Lidar site. The main conclusions are shown as follows:

(1) An integrated algorithm by considering both advantages of the wavelet covariance transform and the improved maximum variance method was developed, in order to solve the problem of determining PBLH under different aerosol conditions (e.g., weak aerosol layer or another aerosol layer exists).

(2) Nine years of synchronous observations based on the data from Lille Lidar site were applied to validate the PBLH estimated by CALIOP. The comparisons of 


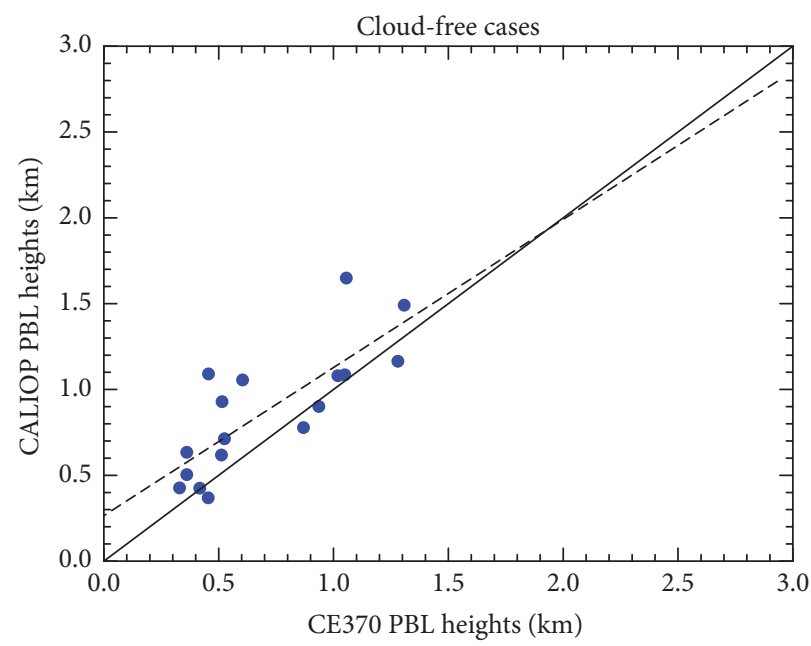

$$
\begin{array}{ll}
\Delta=0.206 \mathrm{~km} & \mathrm{RMSE}=0.222 \mathrm{~km} \\
N=17, R^{2}=0.62, R=0.79 & -1: 1 \text { line }
\end{array}
$$

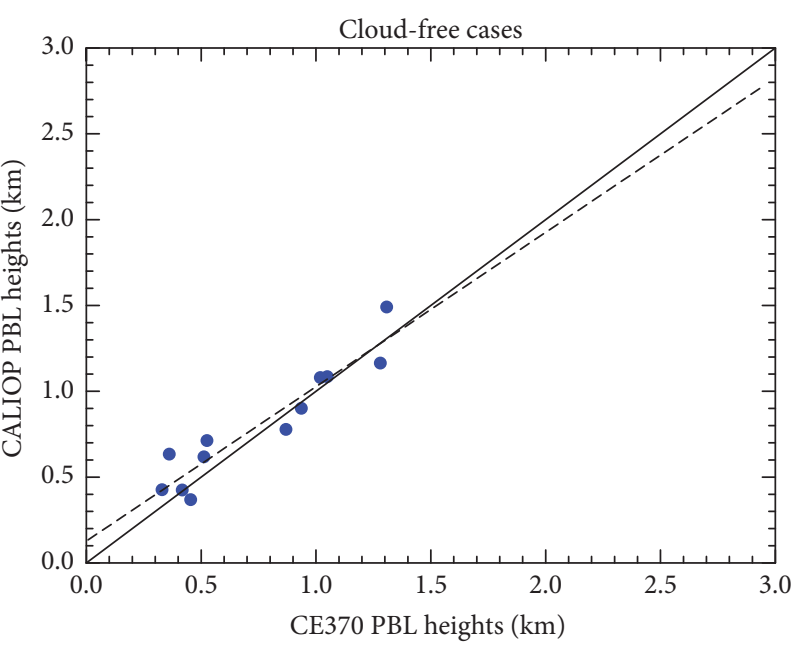

$$
\begin{array}{ll}
\text { Aloft aerosol layers are removed } & \text { RMSE }=0.113 \mathrm{~km} \\
\Delta=0.106 \mathrm{~km} & -1: 1 \text { line } \\
N=12, R^{2}=0.88, R=0.94 &
\end{array}
$$

(b)

(a)

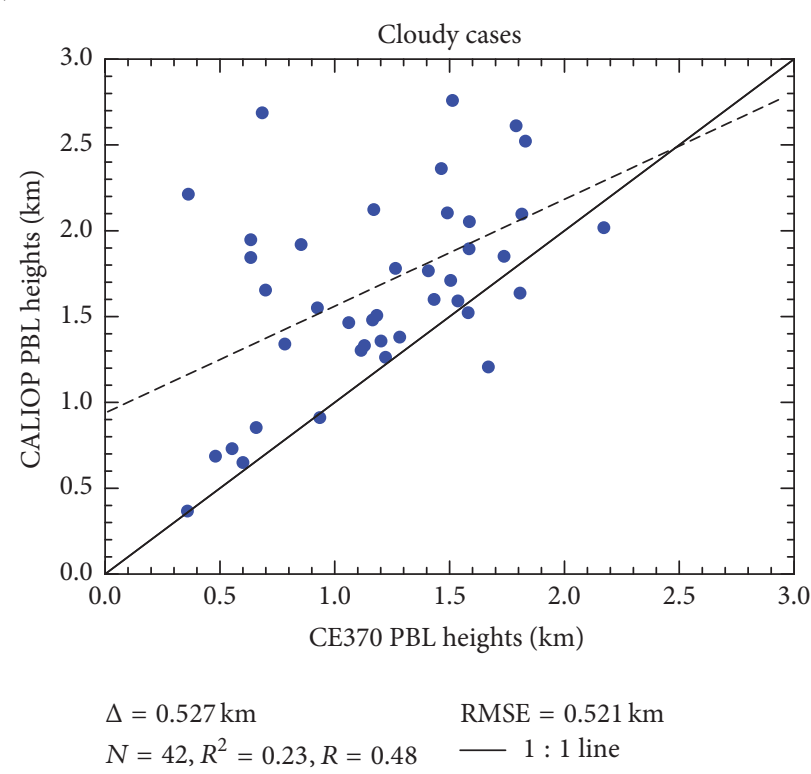

(c)

Figure 11: The correlation of PBLHs derived from CE370 and CALIOP. (a) In cloud-free cases. (b) Result with the removal of the effect of the aloft aerosol layers in (a). (c) The result in cloudy cases.

PBLHs derived by CALIOP and ground-based Lidar show good agreement $(R \geq 0.79)$ under clear sky conditions. The mean absolute differences of PBLHs are, respectively, of $206 \mathrm{~m}$ and $106 \mathrm{~m}$ before and after the removal of the aloft aerosol layer. According to the analysis above, it is implied that the integrated algorithm can effectively estimate the PBLH under clear sky conditions.

(3) The results of distance analysis indicate that the spatial correlation of PBLHs decreases with the increasing spatial distance between CALIOP footprint and Lille observation platform. Besides, the clouds and the aloft aerosol layer have a significant impact on the accuracy of PBLH derived from CALIOP observations. The larger mean absolute difference (i.e., $527 \mathrm{~m}$ ) exists under cloudy sky conditions, even if the cloud masking was applied to the CALIOP data.

In the future, we will further improve and optimize the PBLH estimation algorithm based on CALIOP observations and solve the problem of the effects of the aloft aerosol layer and cloud layer on determination of PBLH. 


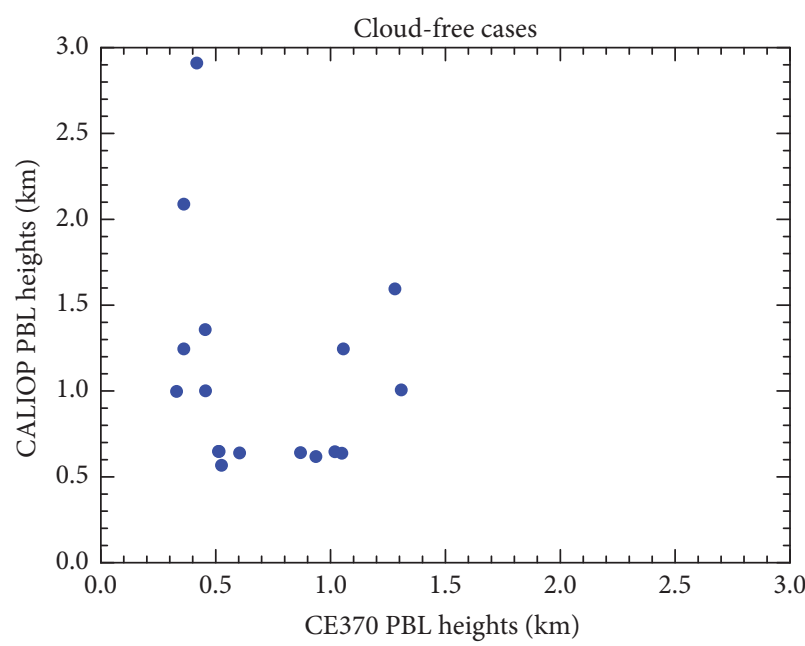

$\Delta=0.571 \mathrm{~km}$

$N=17$

RMSE $=0.596 \mathrm{~km}$

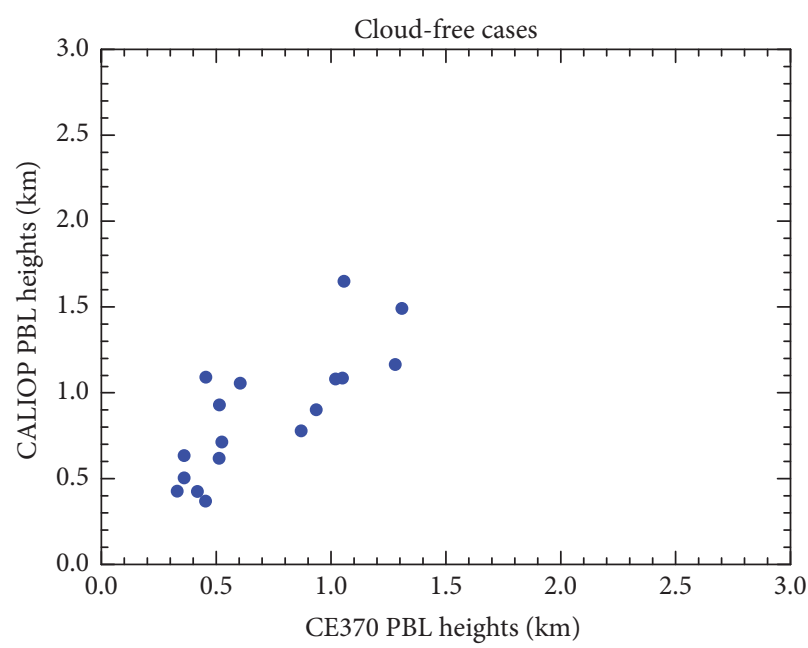

$\Delta=0.206 \mathrm{~km}$

$N=17$

RMSE $=0.222 \mathrm{~km}$

(a)

(b)

FIgURE 12: The comparison results of PBLH derived from CALIOP and CE370. (a) The results of PBLH from CALIOP were derived by the maximum variance method. (b) The results of PBLH from CALIOP were derived by the integrated algorithm.

\section{Conflicts of Interest}

The authors declare no conflicts of interest regarding the publication of this paper.

\section{Acknowledgments}

This work was supported by the National High Technology Research and Development Program of China (no. 2011AA12A104-2), the STS Project of Chinese Academy of Sciences, the Instrument Developing Project of the Chinese Academy of Sciences (no. YZ201664), and the National Natural Science Foundation of China (no. 41671367). The authors would like to thank the whole CALIPSO science team for providing CALIOP data, and they are very grateful to AERONET and PHOTONS for providing AOD and Ångström exponent data.

\section{References}

[1] C. Flamant, J. Pelon, P. H. Flamant, and P. Durand, "Lidar determination of the entrainment zone thickness at the top of the unstable marine atmospheric boundary layer," Boundary-Layer Meteorology, vol. 83, no. 2, pp. 247-284, 1997.

[2] S. Emeis and K. Schäfer, "Remote sensing methods to investigate boundary-layer structures relevant to air pollution in cities," Boundary-Layer Meteorology, vol. 121, no. 2, pp. 377-385, 2006.

[3] R. B. Stull, An Introduction to Boundary Layer Meteorology, Kluwer Academic Publishers, Dordrecht, Boston, London, 1988.

[4] O. P. Cramer, "Potential temperature analysis for mountainous terrain," Journal of Applied Meteorology, vol. 11, no. 1, pp. 44-50, 1972.
[5] W. A. J. Van Pul, A. A. M. Holtslag, and D. P. J. Swart, "A comparison of ABL heights inferred routinely from lidar and radiosondes at noontime," Boundary-Layer Meteorology, vol. 68, no. 1-2, pp. 173-191, 1994.

[6] G. Martucci, R. Matthey, V. Mitev, and H. Richner, "Comparison between backscatter lidar and radiosonde measurements of the diurnal and nocturnal stratification in the lower troposphere," Journal of Atmospheric and Oceanic Technology, vol. 24, no. 7, pp. 1231-1244, 2007.

[7] D. J. Seidel, C. O. Ao, and K. Li, "Estimating climatological planetary boundary layer heights from radiosonde observations: comparison of methods and uncertainty analysis," Journal of Geophysical Research D: Atmospheres, vol. 115, no. 16, Article ID D16113, 2010.

[8] W. P. Hooper and E. W. Eloranta, "Lidar measurements of wind in the planetary boundary layer: the method, accuracy and results from joint measurements with radiosonde and kytoon," Journal of Climate \& Applied Meteorology, vol. 25, no. 7, pp. 9901001, 1986.

[9] P. Seibert, F. Beyrich, S.-E. Gryning, S. Joffre, A. Rasmussen, and P. Tercier, "Review and intercomparison of operational methods for the determination of the mixing height," Atmospheric Environment, vol. 34, no. 7, pp. 1001-1027, 2000.

[10] S. A. Cohn and W. M. Angevine, "Boundary layer height and entrainment zone thickness measured by lidars and windprofiling radars," Journal of Applied Meteorology, vol. 39, no. 8, pp. 1233-1247, 2000.

[11] R. Frehlich, Y. Meillier, M. L. Jensen, B. Balsley, and R. Sharman, "Measurements of boundary layer profiles in an urban environment," Journal of Applied Meteorology and Climatology, vol. 45, no. 6, pp. 821-837, 2006.

[12] C. Milroy, G. Martucci, S. Lolli, and S. Loaec, "On the ability of pseudo- operational ground-based light detection and ranging (LIDAR) sensors to determine boundary-layer structure: intercomparison and comparison with in-situ radiosounding," 
Atmospheric Measurement Techniques Discussions, vol. 20, no. 1, pp. 563-597, 2011.

[13] S. H. Melfi, J. D. Spinhirne, and S.-H. Chou, "Lidar observations of vertically organized convection in the Planetary Boundary Layer over the ocean," Journal of Applied Meteorology and Climatology, vol. 24, no. 8, pp. 806-821, 1985.

[14] K. J. Davis, N. Gamage, C. R. Hagelberg, C. Kiemle, D. H. Lenschow, and P. P. Sulivan, "An objective method for deriving atmospheric structure from airborne lidar observations," Journal of Atmospheric and Oceanic Technology, vol. 17, no. 11, pp. 1455-1468, 2000.

[15] H. Baars, A. Ansmann, R. Engelmann, and D. Althausen, "Continuous monitoring of the boundary-layer top with lidar," Atmospheric Chemistry and Physics, vol. 8, no. 23, pp. 7281-7296, 2008.

[16] L. Menut, C. Flamant, J. Pelon, and P. H. Flamant, "Urban boundary-layer height determination from lidar measurements over the Paris area," Applied Optics, vol. 38, no. 6, pp. 945-954, 1999.

[17] D. G. Steyn, M. Baldi, and R. M. Hoff, “The detection of mixed layer depth and entrainment zone thickness from lidar backscatter profiles," Journal of Atmospheric and Oceanic Technology, vol. 16, no. 7, pp. 953-959, 1999.

[18] V. Sawyer and Z. Li, "Detection, variations and intercomparison of the planetary boundary layer depth from radiosonde, lidar and infrared spectrometer," Atmospheric Environment, vol. 79, no. 11, pp. 518-528, 2013.

[19] I. M. Brooks, "Finding boundary layer top: application of a wavelet covariance transform to lidar backscatter profiles," Journal of Atmospheric and Oceanic Technology, vol. 20, no. 8, pp. 1092-1105, 2003.

[20] S. Emeis, K. Schäfer, and C. Münkel, "Surface-based remote sensing of the mixing-layer height-a review," Meteorologische Zeitschrift, vol. 17, no. 5, pp. 621-630, 2008.

[21] F. Mao, W. Gong, and T. Logan, "Linear segmentation algorithm for detecting layer boundary with lidar," Optics Express, vol. 21, no. 22, pp. 26876-26887, 2013.

[22] F. Mao, J. Li, C. Li, W. Gong, Q. Min, and W. Wang, "Nonlinear physical segmentation algorithm for determining the layer boundary from lidar signal," Optics Express, vol. 23, no. 24, pp. A1589-A1602, 2015.

[23] A. Lammert and J. Bösenberg, "Determination of the convective boundary-layer height with laser remote sensing," BoundaryLayer Meteorology, vol. 119, no. 1, pp. 159-170, 2006.

[24] N. S. Jordan, R. M. Hoff, and J. T. Bacmeister, "Validation of goddard earth observing system-version 5 MERRA planetary boundary layer heights using CALIPSO," Journal of Geophysical Research D: Atmospheres, vol. 115, no. 24, Article ID D24218, 2010.

[25] E. L. McGrath-Spangler and A. S. Denning, "Estimates of North American summertime planetary boundary layer depths derived from space-borne lidar," Journal of Geophysical Research D: Atmospheres, vol. 117, no. 15, Article ID D15101, 2012.

[26] E. L. McGrath-Spangler and A. S. Denning, "Global seasonal variations of midday planetary boundary layer depth from CALIPSO space-borne LIDAR," Journal of Geophysical Research D: Atmospheres, vol. 118, no. 3, pp. 1226-1233, 2013.

[27] W. Zhang, J. Guo, Y. Miao et al., "Planetary boundary layer height from CALIOP compared to radiosonde over China," Atmospheric Chemistry and Physics, vol. 16, no. 15, pp. 99519963, 2016.
[28] S.-W. Kim, S. Berthier, J.-C. Raut, P. Chazette, F. Dulac, and S.C. Yoon, "Validation of aerosol and cloud layer structures from the space-borne lidar CALIOP using a ground-based lidar in Seoul, Korea," Atmospheric Chemistry and Physics, vol. 8, no. 13, pp. 3705-3720, 2008.

[29] D. M. Winker, M. A. Vaughan, A. Omar et al., "Overview of the CALIPSO mission and CALIOP data processing algorithms," Journal of Atmospheric and Oceanic Technology, vol. 26, no. 11, pp. 2310-2323, 2009.

[30] K. Li, Z. Li, D. Li et al., "Transfer method to calibrate the normalized radiance for a CE318 Sun/sky radiometer," Chinese Optics Letters, vol. 13, no. 4, Article ID 041001, 2015.

[31] N. Gamage and C. Hagelberg, "Detection and analysis of microfronts and associated coherent events using localized transforms," Journal of the Atmospheric Sciences, vol. 50, no. 5, pp. 750-756, 1993.

[32] J. Liu, J. Huang, B. Chen et al., "Comparisons of PBL heights derived from CALIPSO and ECMWF reanalysis data over China," Journal of Quantitative Spectroscopy and Radiative Transfer, vol. 153, pp. 102-112, 2015.

[33] S. Groß, M. Esselborn, M. Wirth, A. Fix, and A. Minikin, "Airborne high spectral resolution lidar observation of pollution aerosol during EUCAARI-LONGREX," Atmospheric Chemistry and Physics, vol. 13, no. 5, pp. 2435-2444, 2013.

[34] Y. Wang, H. Che, J. Ma et al., "Aerosol radiative forcing under clear, hazy, foggy, and dusty weather conditions over Beijing, China," Geophysical Research Letters, vol. 36, no. 6, Article ID L06804, 2009.

[35] A. Mortier, P. Goloub, Y. Derimian et al., "Climatology of aerosol properties and clear-sky shortwave radiative effects using Lidar and Sun photometer observations in the Dakar site," Journal of Geophysical Research: Atmospheres, vol. 121, no. 11, pp. 6489-6510, 2016.

[36] A. Mortier, Tendances et variabilités de l’aérosol atmosphérique à l'aide du couplage Lidar/Photomètre sur les sites de Lille et Dakar [Phd. thesis] Optique et laser, Physico-chimie, Atmosphère, French, 2013.

[37] J.-F. Léon, Y. Derimian, I. Chiapello et al., "Aerosol vertical distribution and optical properties over M'Bour (16.96 W;14.39 N), Senegal from 2006 to 2008," Atmospheric Chemistry and Physics, vol. 9, no. 23, pp. 9249-9261, 2009. 

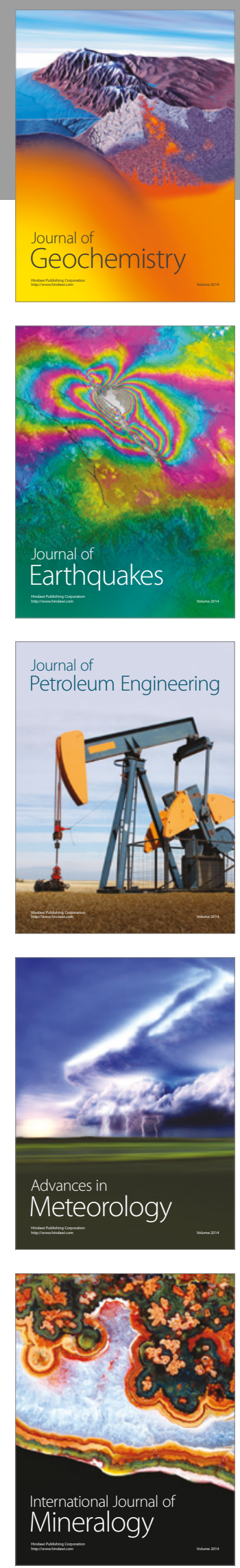
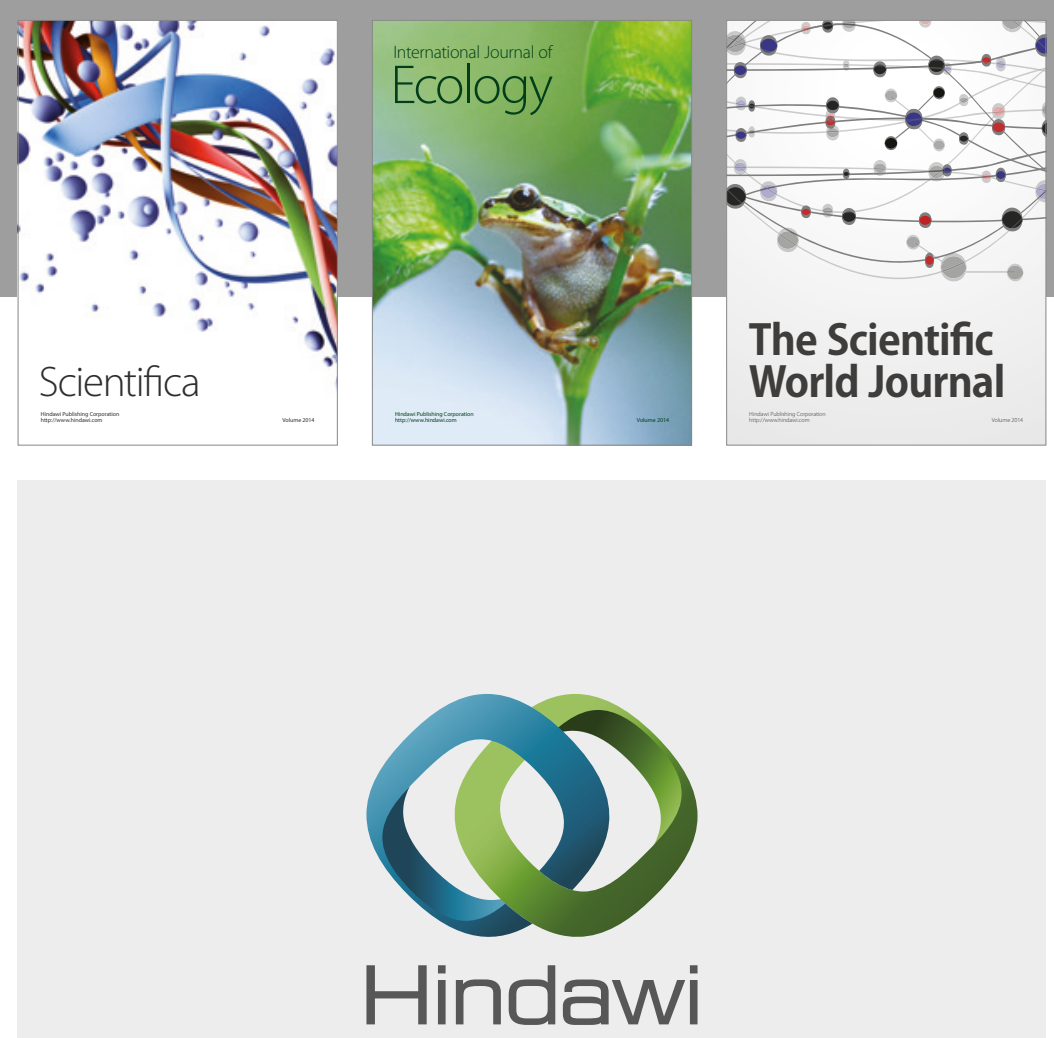

Submit your manuscripts at

https://www.hindawi.com
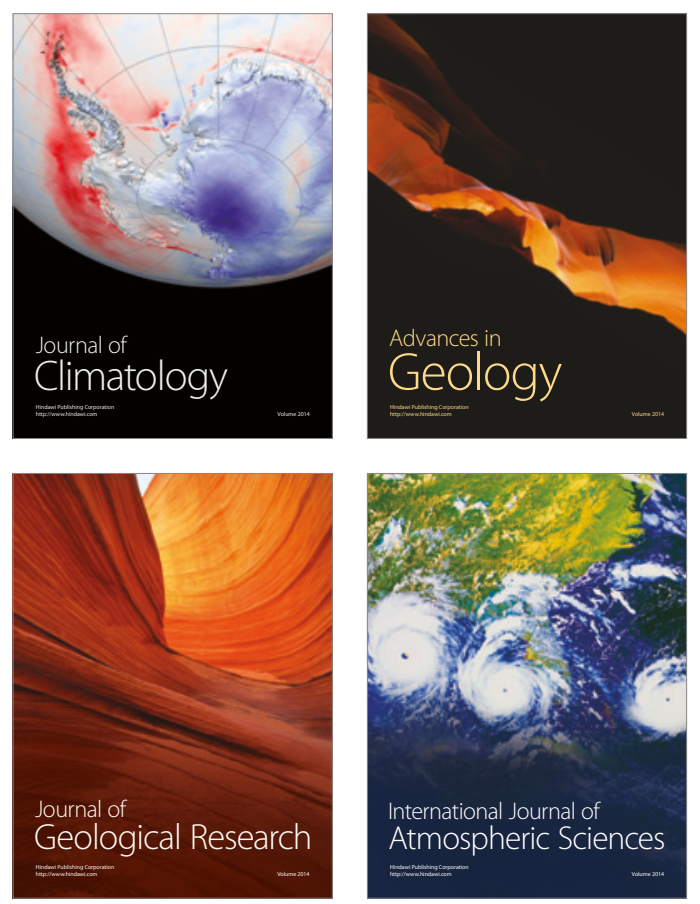

The Scientific

World Journal
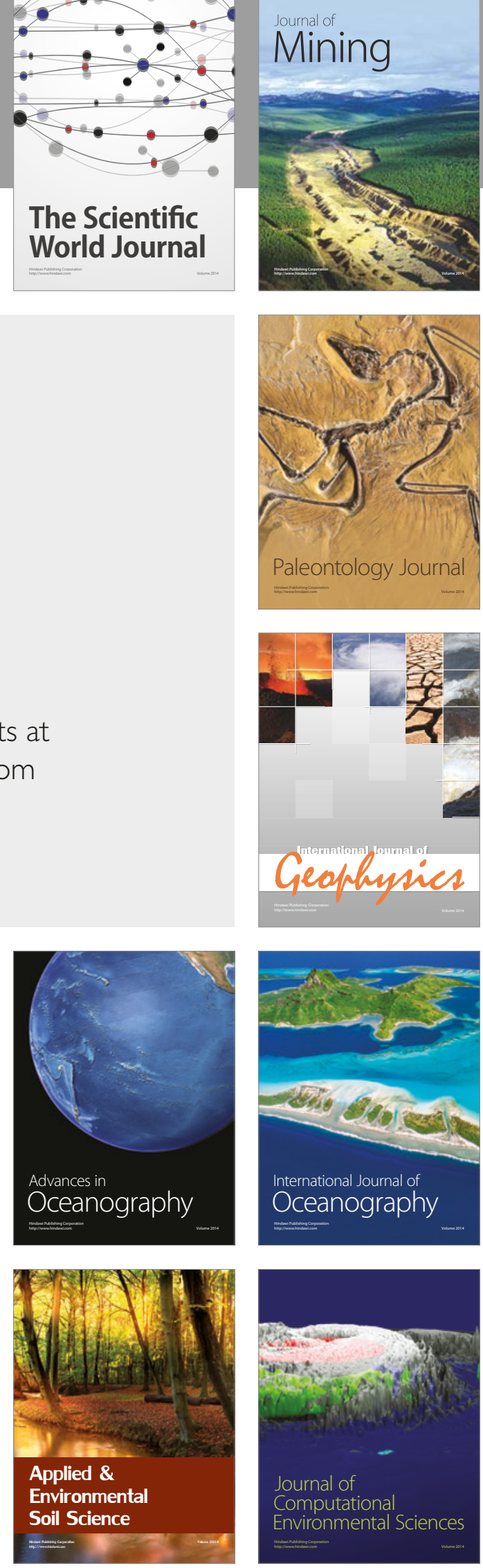